\title{
Common Problems in English Pronunciation Among Chinese Learners and Teaching Implications
}

\author{
Lanqing Zhang* \\ University of Aberdeen, King's College, Aberdeen AB24 3FX, UK
}

\begin{abstract}
In the process of learning any languages, pronunciation is an important part of language acquisition because pronunciation may influence a listener's comprehension of one's expression. An example is the classical mistake of pronouncing "sink" and "think." Because Germans cannot pronounce $/ \mathrm{s} /$, the rescue worker cannot understand why a man who is "thinking" needs help. In China, English learners are also facing the problems of pronunciation. Gimson, a famous professor of linguistics in Britain, pointed out that when learning a language, one should understand $50 \%-90 \%$ of its grammar and $1 \%$ of its vocabulary, but it is necessary to fully master the pronunciation, thus highlighting the importance of pronunciation. ${ }^{[1]}$ However, pronunciation is a difficult part of a second language acquisition. This article analyzes the problems of pronunciation and discuss some methods on how to resolve them.
\end{abstract}

Keywords: English pronunciation; Chinese learners; Teaching implications

Publication date: May, 2021; Publication online: 31 May, 2021

*Corresponding author: Lanqing Zhang, sdzczhanglq@126.com

\section{Theoretical Introduction}

There is a general agreement that the first language (L1) can impact the second language (L2) acquisition. Different L1 backgrounds will lead to various L2 learning outcomes. Cross-language influence, or the transfer of prior knowledge from the first language to the second language, is a process of interlanguage development. ${ }^{[2]}$ Second Language Acquisition (SLA) researchers know that, generally speaking, language transfer is a hot topic in this field. ${ }^{[3]}$ American linguist Lado believed that learners could not get rid of the influence of their mother-tongue when learning a foreign language, and would inevitably transfer the language form, meaning and culture of their mother-tongue to foreign language learning, thus affecting foreign language learning. ${ }^{[4]}$ There are two main types of language transfer: positive and negative transfer. A positive transfer occurs when a L1 structure or rule is appropriate or correct. On the contrary, a negative transfer occurs when it is used in a second language and the result is inappropriate or incorrect. $^{[2]}$ That transfer certainly affects pronunciation. In China, some English learners use Chinese Bopomofo or Chinese characters with similar sounds to annotate a new word in order to remember its pronunciation. For instance, "good" can be annotated as “古德” or “gu de”. Although it is helpful sometimes, for most circumstances, learners cannot pronounce a word accurately. Since some phonemic contrasts are not present, learners cannot use the same Chinese pronunciation to transfer exactly.

There are 20 vowels and 28 consonants in the English phonetic alphabet, which are 48 in total. They have various manner of articulation. There are 34 provinces and 56 ethnics in China. Almost every area has its own local dialect. Therefore, different dialects have different influences on the English pronunciation. It can be roughly divided 
into northern and southern accent. Chongqing, a southern city, is an example. There are only 19 initials in the Chongqing dialect. In English, there are 24 consonant phonemes. In addition, English / $\theta$ / and /e/ have a unique set of consonants that are not found in Mandarin or the Chongqing dialect. In Chongqing dialect, /s/ is similar but is pronounced in a completely different way from this group of consonants. Therefore, Chongqing students often pronounce this group of sounds as /s/ and /z/. Another major characteristic of Chongqing dialect in consonants is that " $\mathrm{n}$ " and " $\mathrm{l}$ " are not divided in this dialect. The dialect is transferred to English phonetics, leaving students in Chongqing unable to correctly read and hear words beginning with consonants " $n$ " and " 1 ". For example, they cannot distinguish the pronunciation of "night" and "light," because for Chongqing people, all the words read beginning with a /l/ became /n/. The third characteristic of Chongqing dialect is the division of $/ \mathrm{h} /$ and $/ \mathrm{f} /$. Some Chongqing people usually pronounce words beginning with initial /f/ as /h/ and add a $/ \mathrm{u} /$ after $/ \mathrm{h} /$. In addition, Chongqing dialect does not have the sound of $/ \mathrm{v} /$, and words beginning with /v/ are usually pronounced as /w/. ${ }^{[5]}$ Those are just the negative transfer of English consonant pronunciation in the initial system of Chongqing dialect.

In north of China, Gansu province can be a typical example. In Mandarin, there are opposites of aspirated sounds and unaspirated sounds: b-p, d$\mathrm{t}, \mathrm{g}-\mathrm{k}$, but people in Gansu cannot distinguish them. Under this influence, when learners read words like "spring," "string," "scream" and so on, they pronounce voiced consonants /b/, /d/, /g/ as blasting voiceless consonants /p/, /t/, /k/. They usually mix the similar $/ \mathrm{n} /$ and $/ \mathrm{n} /$ sounds in English, leading to the mixing of words such as king/kin, sing/sin, song/son, etc. In addition, nasal endings cause the nasalization of English vowels. Words that do not have a nasal sound, such as back, had, are often mispronounced as bank, hand. It is difficult to learn abrasives $/ \mathrm{t} / \mathrm{d} / \mathrm{d} z /$ and fricatives $/ \mathrm{J} /$ in many parts of Gansu, making sounds like sleep, question and shine become ambiguous and unclear. Besides, there are no frictional voiced consonants in Gansu dialect and Mandarin; therefore, students often use $/ \mathrm{r} /$ instead of $/ 3 /$ in "road", "rose", "vision", "pleasure" and other words. ${ }^{[6]}$ Improper transfer of L1 to L2 is a "foreign accent" that is detectable in the speech of non-native speakers and is probably the most common and easily identified aspect of L1 influence. ${ }^{[2]}$

\section{Background Data}

Data (Table 1) was compiled based on a 5-minute interview recording of a participant's conversation. The interviewee is from Heilongjiang province. $\mathrm{He}$ is in his twenties and has been learning English for about 15 years. He has taken the IELTS test, with a speaking score of 5.5 and received higher education. He grew up in the North and spent most of his life in the cities of Northeast China. As a result, he can speak a native northeastern dialect.

\section{Case Analysis}

The short interview cannot expose all problems, so the case will be analyzed from limited points of view. According to the Standard Test of Putonghua guidelines, the northeastern dialect is a dialect based on Shandong and Hebei dialects, mainly distributed in Heilongjiang, Jilin, Liaoning, Inner Mongolia Autonomous Region and nearby areas. The effect of L1 on L2 acquisition is similar in these provinces. However, because the northeastern dialect is similar to Mandarin, there is little research on the transfer effect of the northeastern dialect on SLA. ${ }^{[7]}$ As a matter of fact, the characteristics of the northeastern dialect are complex, which are still quite different from Mandarin, and have a significant transfer effect on English learning, especially in pronunciation.

Firstly, one of the distinguishing features of northeastern dialect is rhotic accent. Although many northern dialects have the habit of rhotic pronunciation, the phenomenon is more frequently in the northeastern dialect than in other dialects. When they learn English, the Northeastern people tend to be accustomed in adding $/ \mathrm{r} /$ after every $/ \mathrm{\partial} /$ and $/ \Lambda /$ sound, so they are not used to making $/ \partial /$ and $/ \Lambda /$ without retroflex consonant. For example, they will pronounce was (17) /woz/ as /worz/. 
Table 1. 5-minute interview recorded in the participant's conversation

Key: Interviewer $=\mathrm{I}$, Participant $=\mathrm{P}$

\section{Noticeable divergences from Standard BE Pronunciation}

1 I: What have you been up to lately?

2 P: Well, you know my major is aircraft flying technology, so I have been

3 prepared my flight tests recently and I also do some preparation for

4 going abroad.

$5 \quad$ I: Wow, that's sounds nice. Which country will you go?

6 P: I will go to Canada.

7 I: Have you applied a University?

8 P: Yes, sure.

9 I: Which one?

10 P: Sorry I want to keep it a secret for now.

11 I: It's okay. Have you ever looked for an internship before?

12 P: Yes of course, but I don't like it.

13 I: Can you tell me why?

14 P: So tired and the work mission is boring, and the working hours are

15 extremely long. It was about 10 hours a day, so I quit that job.

16 I: Why not changed one?

17 P: I was thinking of changing companies as an intern, but the interview

18 failed, so I just gave up, also because the exam is getting closer and

19 closer, and I want to spend most of my time reviewing exam content.

20 I: Okay, it is also a good choice. What's your plan? I mean what will you

21 do after graduation from the University? be a pilot?

22 P: Yes, I have signed with an airlines company recently. They promised

23 me to enter the company as soon as I came back from studying abroad

24 I: Wow congratulations! Well, what type are you studying? I mean

25 general education or Civil Aviation?

26 P: I'm major in Civil Aviation

27 I: That sounds cool! I hope one day I can take the plane you fly.

28 P: It is my pleasure.

29 I: Ha ha ha ha. When is your exam?

30 P: Next month.

31 I: That's closed, I'm sorry to disturb your preparation.

32 P: It's okay, no matter. That's won't take too much time, I think.

33 I: Yes, I will keep it under 5 minutes. I know you've taken the IELTS

34 exam, what do you think is the hardest part about learning English?

35 P: Well I think the speaking skills is difficult to improve, you know my

36 pronunciation is not good and it's hard to correct, because it has become

37 a habit.

38 I: Yes, I know.

39 P: But I'm trying my best to make a progress.

40 I: That's good. I hope you can be successful.

41 P: Thank you. Maybe studying in Canada will be a great promotion for

42 my pronunciation.

43 I: Yes, it certainly will. OK, that's the end of our conversation, thank you.

Numbers stated in brackets after example words refers to the numbers at the left column in Table 1. 
Secondly, the classification of unit sounds in English is more complex than single vowels in Chinese pinyin, and it is also more complex than single vowels in northeastern dialect. As a result, people in the Northeast region who are learning English are always unable to completely distinguish between the various vowels in English. In addition, the pronunciation of vowels in Northeast China is very casual, with a completely relaxed mouth and a very small mouth opening, while English vowels are pronounced with different mouth shapes and tongue positions, which makes it difficult for Northeast people to learn. For example, they always use pinyin "e", a vowel that can be pronounced with a slight opening of the mouth instead of the tight and rounded "o". Transferring to English learning, it is hard for an original learner to distinguish between /i:/, /I/ and /e/, and they always read /i:/ as /I/ because the latter is easier to read. Such as, secret (10), extremely (15), civil (26). Another typical example is that it is not easy for people from the Northeast region to learn the pronunciation of /æ/. Probably due to their easy-going personality, they are not used to opening their mouths wide, so they just casually pronounce the pinyin "ai". Besides, when they pronounce the complex vowels in Chinese pinyin, they can randomly open their mouths to produce similar sounds. Such as, back (23), exam (18), have (22). The same thing happens when they are reading diphthongs in English. Diphthong in English requires the speaker to slide from the first unit to the second, thus forming a diphthong. When Northeast people are practicing diphthongs, they do not slide and pronounce the diphthongs as a unit. They read the /av/ as /o:/, /ai/ as /e/, and read /ov/ also in an inaccurate way. Such as, like (12), flight (3), about (15).

Another distinctive feature of the northeastern dialect is that the Northeastern people cannot clearly distinguish between rhotic sounds of pinyin, such as " $\mathrm{zh} / \mathrm{ch} / \mathrm{sh}$ " and non-rhotic sounds such as "z/c/s". Northeastern English learners cannot distinguish /z/, /s/ and /dz/, /t $/$ /, / / / well. Therefore, they may prefer to replace English consonants with similar Chinese consonants. Such as, sure (8), pleasure (28). Last but not least, Northeastern people also have difficulty in distinguishing /w/ from $/ v /$, that is similar to the influence of most Chinese dialects. For example, interview (17).

\section{Teaching Implications}

The native language plays a crucial role in the learning of a second language, and the influence of Chinese language on Chinese English learners cannot be neglected. There are countless dialects in China, whereby each dialect has a different impact on L2 pronunciation. It is important for an English teacher to solve the problem according to the actual situation. In order to help students to learn English effectively, teachers need to focus on the negative transfer effect of local dialects on English phonetic learning. Students should be guided and inspired correctly to help them avoid the impact of negative transfer so as to improve their learning efficiency.

Besides dialects, age is another aspect that needs to be considered. The effects of age on both L1 and L2 acquisition are discussed in the Critical Period Hypothesis. Lenneberg proposed that if there is brain damage to the language area of a child, the child has only a limited number of years to master the mother tongue perfectly. ${ }^{[8]}$ This is because the plasticity of the brain in childhood allows certain other areas of the brain to replace damaged areas for language learning. However, if a child is beyond a certain age, normal language is not possible. While Bialystok claims that adults usually do not notice small differences, while children do and tend to create new categories accordingly. ${ }^{[9]}$ She believes this is a difference in cognitive style, not because of a critical or sensitive period, which may explain why many people think children are superior in L2 learning. Since the relationship of age and style is a tendency, not an absolute, children may pronounce L 2 with a foreign accent, but it is highly unlikely that adults will acquire a native-like pronunciation, but they are less likely to do so. In other words, learners past puberty are likely to fail to achieve near-native pronunciation in any case, no matter how much effort they put into their learning. ${ }^{[2]}$ Therefore, English learning especially at the primary school 
level requires correct pronunciation guidance, and first impressions are usually crucial. This requires teachers to have good pronunciation habit and correct children's pronunciation mistakes immediately.

There are some following methods of how to overcome the negative transfer on L2 pronunciation. Nowadays, social applications are getting more advanced. In China, people often use WeChat to communicate with each other. When people are using the WeChat application, they can send a piece of voice message. Therefore, teachers can assign a voice assignment to students and ask them to hand in their homework via WeChat. Then, teachers will listen to every student's message and provide accurate correction one by one. In that way, teachers may know everyone's advantages and disadvantages. This avoids situations whereby teachers cannot guide everyone because of the limited class time. Another effective way is that teachers can play videos or audio recordings of standard spoken English, for example, BBC Learning English in class, which students can imitate. Teachers should definitely choose materials according to the level of the student. Furthermore, learners can use some educational applications, for instance, English Fun Dubbing (EFD). As a type of English learning app, EFD is welcomed by numerous English learners as it has a wide array of video clips and adopts a unique mode for language learning. ${ }^{[10]}$ Users may repeat after the soundtrack of a video or read after it. The materials include films, documentaries, short videos and so on. Then, the system will correct user's mistakes, give a score, and suggestions for improvement will also be given accordingly. Besides, EFD has its own online community that users can exchange learning experiences and encourage each other. Table 2 briefly shows a lesson plan of pronunciation teaching.

Table 2. A lesson plan of pronunciation teaching

Presentation \& Practice Activity: Diphthongs (All levels)

Materials: An English song

Aim: For students to be able to discriminate and to practice production of phonemes /ai/, /ei/.

\section{Stage 1}

1. Listen to the English song <you are my sunshine>

2. Show them whole lyrics on the blackboard

3. Let them circle the words which include /ai/ and /eI/

Stage 2

1. Introducing these two phonetic symbols in detail

2. Give some examples

3. Practising with a partner

\section{Conclusion}

In summary, L1's influence on L2 is deeply ingrained. Although we cannot completely eliminate the inappropriate transfer of $\mathrm{L} 1$ pronunciation, we should practice correct pronunciation as much as possible. In the current article, because of the limited space, it is hard to include all types of Chinese dialects. Therefore, some of the negative transfer effects of dialects are not mentioned. However, the article still covers most of the common questions. There are many appropriate methods to improve one's pronunciation. Thus, both teachers and learners should make good use of resources to solve problems.

\section{Disclosure statement}

No conflicts of interest.

\section{References}

[1] Gimson, A(1980). An introduction to the pronunciation of English (3rd ed.). Edward Arnold. Retrieved from https://abdn.primo.exlibrisgroup.co 
$\mathrm{m} /$ discovery/fulldisplay?context $=\mathrm{L} \& \mathrm{vid}=44 \mathrm{ABE}$ INST:44ABE_VU1\&search_scope=MyInst_and_ CI\&isFrbr $=$ true \&tab=Everything $\&$ docid=alma990 000965000205941

[2] Saville-Troike, M(2006). Introducing second language acquisition. Cambridge University Press. Retrieved from https://abdn.primo.exlibrisgroup.co m/permalink/44ABE_INST/1jd7019/alma9900110 69100205941

[3] Ringbom, H(1990). Language transfer. Crosslinguistic influence in language learning: Odlin, Terence, Cambridge: Cambridge University Press, 8(3):392-393. Elsevier Ltd. Retrieved from https://doi.org/10.1016/0346-251X(90)90015-W [4] Lado, R(1963). Linguistics across cultures: applied linguistics for language teachers. Retrieved from https://abdn.primo.exlibrisgroup.com/permal ink/44ABE_INST/1jd7019/alma990002937650205 941

[5] Hongwei, $\mathrm{J}(2010)$. The negative transfer of Chongqing Dialect in English phonetics learning. Exam Journal, (29):101-102. Retrieved from https://kns.cnki.net/kcms/detail/detail.aspx?FileNa me $=$ KDZK201029083 $\&$ DbName $=$ CJFN2010

[6] Shixia, H(2014). A Study on the Negative Transfer of Gansu Dialect in English Phonetics Learning. Journal of Longdong University, (06):45-47. Retrieved from https://kns.cnki.net/kc
ms/detail/detail.aspx?FileName=LDXS201406011 $\&$ DbName $=$ CJFQ2014

[7] Yongna, $M(2018)$.The Negative Transfer effect of Northeast Dialect in English Phonetics Learning. Short Story (Original version), (11):120-121. Retrieved from https://kns.cnki.net/kcms/detail/de tail.aspx ?FileName $=$ DPXS201811056\&DbName $=$ CJFN2018

[8]Lenneberg, E., Chomsky, N., \& Marx, O(1967). Biological foundations of language. Wiley. Retrieved from https://abdn.primo.exlibrisgroup.co m/permalink/44ABE_INST/1jd7019/alma9900031 02900205941

[9]Bialystok, E., \& Hakuta, K(1994). In other words: the science and psychology of secondlanguage acquisition. Basic Books. Retrieved from https://abdn.primo.exlibrisgroup.com/discovery/fu lldisplay?context=L\&vid=44ABE_INST:44ABE_ VU1\&search_scope=MyInst_and_CI\&tab=Everyt hing\&docid=alma990010777270205941

[10]Chuanpeng, T(2019). A Study on the Influence of English Fun Dubbing App on English Pronunciation level of College Students (Master's degree thesis, Central China Normal University). Retrieved from https://kns.cnki.net/KCMS/detail/d etail.aspx ?dbname $=$ CMFD202001\&filename $=101$ 9249452.nh 